\title{
Journal of Athlete Development and Experience
}

March 2019

\section{"Support is What Really Helped Me Get Through": Understanding Athletes' Online Disclosures about Pursuit and Receipt of Social Support During Concussion Recovery}

Jimmy Sanderson

Texas Tech University, jimmy.sanderson@ttu.edu

David Cassilo

Kent State University, dcassilo@gmail.com

Follow this and additional works at: https://scholarworks.bgsu.edu/jade

Part of the Higher Education Commons, Sports Management Commons, and the Sports Studies Commons

How does access to this work benefit you? Let us know!

\section{Recommended Citation}

Sanderson, Jimmy and Cassilo, David (2019) "'Support is What Really Helped Me Get Through": Understanding Athletes' Online Disclosures about Pursuit and Receipt of Social Support During Concussion Recovery," Journal of Athlete Development and Experience: Vol. 1: Iss. 1, Article 3. DOI: https://doi.org/10.25035/jade.01.01.03

Available at: https://scholarworks.bgsu.edu/jade/vol1/iss1/3

\section{(1) (9)}

This work is licensed under a Creative Commons Attribution-NonCommercial 4.0 International License This Research Article is brought to you for free and open access by the Journals at ScholarWorks@BGSU. It has been accepted for inclusion in Journal of Athlete Development and Experience by an authorized editor of ScholarWorks@BGSU. 


\title{
"Support is What Really Helped Me Get Through": Understanding Ath- letes' Online Disclosures about Pursuit and Receipt of Social Support During Concussion Recovery
}

\author{
Jimmy Sanderson \\ David Cassilo \\ Texas Tech University \\ Kent State University
}

Sanderson (Jimmy.Sanderson@ttu.edu) is corresponding author.

\begin{abstract}
This research examines the role of social support in athletes' lived experiences with concussion injuries. Fifty-eight blog posts authored by athletes documenting their concussion injuries were analyzed to determine the types of support athletes sought and received while rehabilitating from a concussion. A deductive approach guided by Xu and Burleson's (2001) social support typology guided analysis of the blog posts. Results indicated that to varying degrees, athletes sought and received emotional, informational, network, esteem, and tangible support. Analysis revealed that athletes experience support deficits with esteem and emotional support, while they appear to have network support needs met. The results enhance understanding of athletes' lived experiences with concussion symptoms and their support needs as they recovered from this injury. The results also illustrate the types of support that parents, friends, teachers, teammates, coaches, and others can enact to better support athletes through concussion management.
\end{abstract}

Keywords: : Online Forums, Supportive Communication, Athletes And Health, Sport Concussions, Health Stigmas

Estimates suggest that 1.6 to 3.8 million concussions occur each year in the United States due to participation in sport or recreational activities (Baugh, Kroshus, Daneshvar, \& Stern, 2014; Langlois, Rutland-Brown, \& Wald, 2006). These incident rates arguably have contributed to concussions and head injuries in sport being viewed as a public health issue in the United States (Baugh et al., 2014; Baugh \& Shapiro, 2015). Although scholars have examined reasons that athletes do not report concussions (Cranmer \& Labelle, 2018; Kroshus, Garnett, Hawrilenko, Baugh, \& Calzo, 2015c; Sanderson, Weathers, Snedaker, \& Gramlich, 2017), less attention has focused on athletes' lived experiences as they manage concussion recovery (Caron, Bloom, Johnston, \& Sabiston, 2013; Cassilo \& Sanderson, 2018; Covassin, Crutcher, Bleecker, Heiden, Dailey, \& Yang, 2014), a process that often is characterized by social isolation and mental anguish (Baugh et al., 2014; Kroshus, Kubzansky, Goldman, \& Austin, 2015a; Weinberg, Vernau, \& Horn, 2013).

Concussion rehabilitation also can be taxing for athletes due to self-perceptions that they are disappointing their coaches and teammates by not playing (Anderson \& White, 2017; Sanderson, et al., 2017). Additionally, concussion recovery also can include limiting exposure to light, loud noises, and TV/mobile devices
(MacDonald, Patel, Young, \& Stuart, 2018), restrictions that may exacerbate perceptions of social isolation. For athletes attending school, concussion rehabilitation often necessitates academic accommodations (Blackwell, Robinson, Proctor, \& Taylor, 2017). However, obtaining academic support can be a difficult task, as some teachers are insufficiently educated about concussion symptoms (Kasamatsu, Valvich McLeod, Register-Mihalik, \& Welch Bacon, 2017) or may resist providing accommodations altogether (Cassilo \& Sanderson, 2018).

As athletes often are reticent to report concussions (Kerr, Register-Mihalik, Kay, DeFreese, Marshall, \& Guskiewicz, 2018; Sanderson et al., 2017), they also may be hesitant to talk about their concussion recovery in traditional settings. Nevertheless, understanding athletes' lived experiences with concussions is crucial for those working and living with athletes, including those who are responsible for sport governance and policy (Liston, McDowell, Malcolm, Scott-Bell, \& Waddington, 2016; Cassilo \& Sanderson, 2018). Whereas talking about concussion recovery can be challenging, online forums offer a compelling space for athletes to share these experiences in a narrative format (Hartill, 2014), which empowers them to shape and disclose their reality in personally meaningful ways (Horton, Bloom, \& Johnston, 2002; Cassilo \& Sanderson, 2018). 
Moreover, people often turn to computer-mediated domains to obtain support when it is difficult to achieve from offline relational partners, and when they feel uncomfortable discussing issues face-to-face (Green-Hamman, Eichhorn, \& Sherblom, 2011; Green-Hamman \& Sherblom, 2014).

Researchers also have noted that understanding behavior in online domains are equally as important to understand as behavior that occurs in offline settings (Hallett \& Barber, 2014) and that not all people feel comfortable discussing their experiences in face-to-face formats (Price et al., 2018). Online forums also are appropriate venues to examine when health stigmas are being investigated and can offer rich insights into how people navigate these health issues (Hanna \& Gough, 2016). For instance, researchers have explored online forums to understand people's experiences with anorexia (Day \& Keys, 2008) and depression (Gough, 2015). For athletes, asking for help or talking about their support needs can be difficult, given the strong masculine norms permeating sport culture that often stigmatize those who ask for assistance (Delenardo \& Terriom, 2014). Researchers also have observed that online forums allow people to navigate new experiences that impact identity (e.g., newborn mothers) without fear of judgment or doing something wrong (Johnson, 2015; Price et al., 2018). Consequently, online forums provide a venue for athletes to share their support needs while recovering from concussions in a domain where they can disclose these experiences with minimal stigmatization and judgment from others.

Scholars also have posited that more information is needed to understand the role of social support in athletes' concussion management processes (Caron, Bloom, Johnston, \& Sabiston, 2013; Covassin et al., 2014). This research seeks to address that gap by examining athletes' support seeking and support fulfillment while recovering from a concussion injury, expressed via personal narratives in online forums.

\section{Review of Literature}

\section{Athletes, Concussions, and Health Stigmas}

Although many sport-related concussions occur annually (Langlois et al., 2006), researchers have found that athletes are hesitant to report concussions due to concerns about being perceived as weak, not being a good teammate, not being believed, or due to pressure from coaches, teammates, fans, or parents (Cranmer \& LaBelle, 2018; Kroshus et al., 2015a; Sanderson, et al., 2017; Weinberg et al., 2013). Coupling these self-perceptions with the physiological, emotional, social, and mental effects of concussions (Bloom, Horton, McCrory, \& Johnston, 2004; McCrory et al., 2017), athletes may perceive concussions as a health stigma, or, "an individual's perception that her or his health condition represents a mark of discredit"
(Wright \& Rains, 2013, p. 310). While certainly attributable to concussive symptoms, these self-perceptions also are influenced by sport cultural norms that privilege hegemonic masculinity (Trujillo, 1991). This version of masculinity is a narrow and strict construction, that in sport, influences athletes to play through pain and to not seek treatment for injuries (Charlesworth \& Young, 2004). Indeed, some athletes willingly assume the health risks associated with not reporting injuries to avoid the negative labeling and stigmas that accompany disclosing injury (Delenardo \& Terrion, 2014).

Rohde et al. (2018) suggested that health-related stigmas could be classified as: (a) enacted - which involves social discrimination toward those with a disease; (b) perceived - the self-perception of discrimination a person believes is being directed at her/him; and (c) internalized - the degree to which a person feels that the discrimination against her/him is warranted. Health stigmas are associated with a variety of negative outcomes, such as reduced support networks, increased health problems, stress, and depression (Wright \& Rains, 2013). Disclosing stigmatized health conditions is risky, as people can encounter social rejection and other consequences (Rains, 2014). Therefore, some people choose to conceal their illness rather than risking the social labeling that will accompany its disclosure (Scambler \& Hopkins, 1986).

The stigma associated with concussions suggest that social support may play a pivotal role in recovery (Caron et al., 2013). Researchers have observed that supportive communication may prompt athletes to report concussions more frequently (Kroshus, Kerr, DeFreese, \& Parsons, 2017), and also helps athletes recovering from injuries to feel more satisfied (Covassin et al., 2014). For instance, Caron et al. (2013) found that family support was crucial for former NHL players managing concussion symptoms after retiring. A stronger understanding about the types of social support athletes seek and receive as they recover from concussions also can enhance concussion education and programming (Kroshus, Baugh, Daneshvar, Nowinski, \& Cantu, 2015b), by helping families, friends, teammates, and others to enact requisite social support that meets athletes' needs during concussion recovery.

\section{Social Support}

Social support has been conceptualized as, "verbal and nonverbal communication between recipients and providers that reduces uncertainty about the situation, the self, the other, or the relationship and functions to enhance a perception of personal control in one's experience" (Albrecht \& Adelman, 1987, p. 19). Whereas scholars have advanced varying models and frameworks for social support (Cutrona and Suhr, 1991; Cutrona \& Russell, 1990; House, 1981), Xu and Burleson's (2001) typology commonly is used by researchers (High \& 
Steuber, 2014). This typology classifies social support as: (a) informational support - which involves providing factual information or advice about a problem; (b) emotional support which is typified by communicating camaraderie and allowing others to vent negative feelings; (c) esteem support - which involves bolstering a person's sense of self-worth; (d) network support - which is typified by increasing people's social resources, often through interpersonal interactions; and (e) tangible support - which involves offering aid to improve a person's life circumstances.

One of the challenges to providing social support is enacting the type of support that the recipient is seeking (Cutrona, 1990; Toller, 2011). The requisite support that is needed varies by the type of situation a person is dealing with (Goldsmith, 2004), along with one's preference for particular types of support (Priem \& Solomon, 2015). Cutrona (1996) observed that when support preferences are violated, frustration results. Conversely, when the support provided matches the support being sought, recipients are more likely to accept it. Providing requisite social support also can help people re-frame a situation and perceive it as less threatening or better understand how to cope with it (Cuntrona \& Cole, 2000; Prieem \& Solomon, 2015). Other barriers to providing satisfactory social support include recipients evaluating that the correct type of support was enacted, but that it was not provided at an adequate level (Xu \& Burleson, 2001), along with recipients concerns that they will be perceived negatively because of their need for support (Bolger \& Amarel, 2007).

Given the frustration and anger that can result when social support does not match the type or level sought, along with self-efficacy concerns that are particularly relevant to athletes (Steinfeldt, Vaughan, LaFollete, \& Steinfeldt, 2012), online forums represent a safe space where athletes can disclose their support needs. Indeed, sport cultural norms that privilege toughness may prevent an athlete from speaking up and sharing how she/he needs help/support to avoid being perceived as weak (Sabo, 2004). Thus, online forums function as a domain where athletes can voice this need with minimal judging and in a space where empathetic others, including those who have undergone similar experiences can be located (McCosker, 2018; Zhao \& Basnyat, 2018).

\section{Social Support and Online Support Forums}

The proliferation of blogs, online communities, and social media sites have amplified the ability for people to obtain support resources (Meng, Chung, \& Cox, 2016; Nabi, Prestin, \& So, 2013). Reports indicate that approximately 1 in 5 Internet users in the United States have gone online to find those with similar health concerns (DeAndrea, 2015). The use of online tools for talk about health and illness also is increasing (Hanna
\& Glough, 2016). Tanis (2008) posited that online forums possessed the following characteristics that made them appealing to users: (a) text-based; (b) anonymity; and (c) extending social networks. Online forums also allow people to connect with similar others across boundaries of space and time (DeAndrea, 2015).

For individuals who believe they have a health stigma, computer-mediated support groups are a viable pathway to obtain support (Wright \& Rains, 2013). Online forums allow people to share their experiences in ways that are personally meaningful in venues where social norms are minimized (Varga \& Paulus, 2014), and to share aspects of their identity where fears of repercussion are minimized (DeAndrea, 2015). In some online support forums and groups, there is a high presence of lurking (Han, Kim, Yoon, Shim, McTavish, \& Gustafson, 2012), which allows users to benefit from community knowledge without feeling pressured to disclose their experiences.

Accordingly, online forums provide unique spaces for athletes to share their concussion recovery experiences in ways that are personally meaningful (Varga \& Paulus, 2014) and to convey information they may not disclose offline. These outcomes are particularly salient given the stigmas associated with sport cultural norms surrounding athletes and toughness (Sanderson et al., 2017). Thus, online forums enable athletes, through narratives, to share their experiences with social support as they describe living with their concussion injury. To guide analysis, the following research questions are posed:

RQ1: What types of social support do athletes report seeking during concussion recovery?

RQ2: What types of social support do athletes report as fulfilling their needs during concussion recovery?

\section{Method}

\section{Data Collection}

Data were obtained from a larger project examining athletes' concussion disclosures via public online support group websites. Three online sites were used in the study: (a) ConcussionConnection.com; (b) TheKnockoutProject.org; and, (c)TalkConcussions.com. These three sites specifically were chosen as they included first-person accounts of people experiencing and living with concussion symptoms. Posts on these three sites were in an open-access public forum, and the researchers accessed the blog posts by visiting each website and examining the postings on each site to ascertain suitability to the study. Posts that included an athlete's first-person narrative concussion story were included. Posts that were excluded were those written in second-hand accounts (e.g., by parents) or those that were news-oriented (e.g., information/opinion on concussions in the National Football League). 
We acknowledge that online data collection poses ethical and privacy challenges for researchers. As the data in our study were publicly available, we considered them to fall within the public domain. Walther (2002) posited that the Code of Federal Regulations Title 45, Part 46, Protection of Human Subjects protects communication privacy in personal spaces such as a physician's office, but observed that publicly available Internet archives possess human subjects' exemption as they are similar to a newspaper or Congressional Radio archives. However, we also wanted to protect the athletes, so no personally identifiable information shared in the blog posts is disclosed in reporting our results (e.g., parent name, physician name).

There were a total of 87 posts in the initial sample. However, after reviewing for inclusion criteria (e.g., first-person account), seven posts were excluded from ConcussionConnection.com, and 22 were excluded from TheKnockoutProject.org, leaving 58 posts in the final sample. All posts from TalkConcussions.com were included in the sample. Not all posts included a date of publication, but those that did ranged from February 2013 to May 2016. This time period reflected the earliest published date (February 2013) to posts appearing at the time of data collection (May 2016). The 58 posts included in the final sample were composed of the following number of posts from each of the three sites: ConcussionConnection.com $(n=26)$, TheKnockoutProject. org $(n=23)$, and TalkConcussions.com $(n=9)$. Of the 58 posts included in the sample, the researchers could determine gender (e.g., profile pictures) in 56 of them, resulting in a breakdown of 45 females and 11 males. Exact ages were unclear, but based on narratives the researchers ascertained individuals ranged from high school students to middle-aged adults at the time of their concussion. The 58 users indicated 16 sports in which their concussion occurred, with soccer $(n=16)$ being the most prevalent.

\section{Data Analysis}

To identify social support in athletes' posts, the researchers used a theory-driven deductive approach for qualitative analysis (Cho \& Lee, 2014), in which an a priori template of codes was established (Crabtree \& Miller, 1999). The codes were established based on the categories of Xu and Burleson's (2001) typology. This method allows researchers to analyze manifest and latent meaning of communication, and to systematically code and categorize data using a validated theoretical framework (Atwood, Friedman, Meisner, \& Cassin, 2018). The sentence in each blog post served as the unit of analysis. Consistent with deductive procedures (Cho \& Lee, 2014), analysis was guided by Xu and Burleson's (2001) social support typology, with each support type serving as a theoretical-based coding category (Cho \& Lee, 2014).
Each of the two researchers coded half the sample, which was split using probability sampling techniques, with each half including postings from all three sources in the sample. The posts initially were read with the researchers identifying meaning and patterns in the data (Braun \& Clarke, 2006). This process was done by making notes to indicate the types of support athletes disclosed they were seeking, along with documenting the types of support they reported receiving. These expressions were then compared with Xu and Burleson's (2001) support classification typology to ascertain how athletes' experiences aligned with it. Due to the interpretive nature of the analysis, the researchers allowed for multiple support types to be present in a post, reflecting the individualized nature of support seeking (Priem \& Solomon, 2015). After making notes of the support being sought and received in each post, each researcher returned to the sample to re-read each post to verify these support categorizations. The authors then discussed each individual post in their respective data sets with one another. This allowed the authors to validate their individual coding classifications and also opened up opportunities for clarification and further refinement. Through this process, the authors reached consensus (Kassing \& Sanderson, 2009) on the a priori categories from the typology fitting the data.

\section{Results}

Analysis revealed that athletes sought the following support types as they managed concussion recovery: emotional $(\mathrm{n}=$ $26)$; informational $(n=21)$; network $(n=20)$; esteem $(n=16)$; and tangible $(\mathrm{n}=13)$. Examples from the blog posts are now discussed. To preserve anonymity, the number following each example represents where the post was ordered within the data set. Thus, a comment with the designation (20), indicates the 20 th post in the data set. Comments were taken verbatim, and spelling and grammatical errors were left intact. Table 1 provides a summary of the support-seeking themes.

\section{Seeking Support}

Emotional support. Athletes described diverse emotional support needs. Notably, emotional support was desired because athletes perceived they would benefit if other people understood the actuality of their lived experiences. For example, "Brain injuries cause emotional and mental distress because no one can see them and understand how you really feel" (33); "It's very lonely and no one understands unless they have been through it" (4); and, "It's hard for people to understand the new research on concussions because people are generally stuck in the 'old' attitudes about them" (34). Athletes also indicated they needed emotional support to help offset the psychological and social effects of concussions. Sentiments here included, "I felt like 
there was no one there for me and I honestly didn't care about myself at all" (46); and:

I still struggle with migraines and every time I have a bad one, am sitting alone in the dark, lights off, music off no phone I'm reminded of the depressing reality that I need to accept that maybe I didn't beat this (43).

One athlete shared that the lack of support led to self-doubt and how that compromised recovery:

Even if its just believing you when you say your head hurts or you can't do something. It sometimes gets to the point where if enough people tell me that I am 'milking it' or 'overreacting' to get out of work, I start to believe it myself. I start pushing myself harder to show them that I am truly trying my best and I end up relapsing by the end of the week or sooner (31).

Table 1.

Support Seeking Themes

\begin{tabular}{|c|c|c|}
\hline SUPPORT TYPE & DEFINITION & EXAMPLE \\
\hline Informational Support & $\begin{array}{l}\text { Providing factual } \\
\text { information or advice } \\
\text { about a problem }\end{array}$ & $\begin{array}{l}\text { "Five years later, I still } \\
\text { go doctor to doctor } \\
\text { looking for help" }\end{array}$ \\
\hline Emotional Support & $\begin{array}{l}\text { Communicating } \\
\text { camaraderie and } \\
\text { allowing others to vent } \\
\text { negative feelings }\end{array}$ & $\begin{array}{l}\text { "I felt like there was no } \\
\text { one there for me and } \\
\text { I honestly didn't care } \\
\text { about myself at all" }\end{array}$ \\
\hline Esteem Support & $\begin{array}{l}\text { Bolstering a person's } \\
\text { sense of self-worth }\end{array}$ & $\begin{array}{l}\text { "People were making } \\
\text { fun of me telling me } \\
\text { that concussions } \\
\text { couldn't last that long } \\
\text { and I got accused of } \\
\text { faking it" }\end{array}$ \\
\hline Network Support & $\begin{array}{l}\text { Increasing people's } \\
\text { social resources, often } \\
\text { through Interpersonal } \\
\text { interactions }\end{array}$ & $\begin{array}{l}\text { "You are no longer } \\
\text { able to have the feeling } \\
\text { of being part of a team } \\
\text { and sharing the support } \\
\text { you love" }\end{array}$ \\
\hline Tangible Support & $\begin{array}{l}\text { Offering aid to } \\
\text { improve a person's life } \\
\text { circumstances }\end{array}$ & $\begin{array}{l}\text { "After several fights } \\
\text { with the school, I finally } \\
\text { got all the tutors I } \\
\text { needed for my five core } \\
\text { classes" }\end{array}$ \\
\hline
\end{tabular}

Informational support. Athletes revealed they pursued informational support to better understand their concussion and its effects. One athlete mentioned trying almost any resource for a solution, "If there was a medication, I took it and if there was a new type of therapy, I tried it." (10). The information-seeking process could be lengthy, as evidenced by comments such as, "Five years later, I still go doctor to doctor looking for help" (4).

Network support. Athletes conveyed the need for network support by describing the isolating effects induced by their concussion and their subsequent desire to maintain social connections with others. For example, "Being alone is probably the biggest factor in this; whether it's physically, mentally, or emotionally. Being alone sucks" (57); and, "I was isolated from my friends and my school, yet I felt so awful that I accepted that there was just nothing I could do about it" (40). Athletes also shared that their companionship needs often went unfulfilled, as their concussion had changed the nature of their social relationships, "As time went by, most of my friends started to forget about me. I was out of sight and out of mind to them. Only a few close friends would call and visit me. The isolation was depressing" (31); and, "my friends drifted away from me which is understandable" (57). Athletes also disclosed how their concussion had impacted their team belonging needs, "Watching my teammates play in the state tournament while I sat on the sidelines broke my heart" (21); and "you are no longer able to have the feeling of being part of a team and sharing the support you love" (42).

Esteem support. Athletes also described a desire for empathy, or a need for others to believe their concussion symptoms were legitimately exerting a significant toll. For example, "It was a really hard time for me, not feeling well, not being able to do much of anything, not seeing friends, being alone a lot, and even having people not believe me when I said how I was feeling" (28); "my symptoms were getting so dramatic that I became known as being in lack of better words stupid or slow. It became a joke to everyone and I went along with it" (56); and, "people were making fun of me telling me that concussions couldn't last that long and I got accused of faking it, by people I was very close to and that hurt a lot" (46).

This disbelief extended into the athletic realm, as athletes disclosed how sport cultural norms contributed to the skepticism they encountered. For instance, "'Are you hurt or injured?'which is Coach's speak for 'can you suck it up and play or not?" (51); and, "If you lose a limb, the disability is tangible to the general population but when it is internal, people choose not to believe" (54). One athlete also shared experiencing this lack of support from a physician, "After about 9 appointments with my concussion Doctor, he more or less gave up on me. None of the medicine was working and I was too much of a challenge" (45).

Tangible support. Athletes, particularly those who also were students, revealed a need for tangible support. Here, athletes disclosed the resistance and skepticism they encountered trying to obtain academic accommodations. Sentiments here included, "The only problem I had and still have is that my teachers don't follow it, and they don't allow me to do some of the accommodations, which they are permitted to do" (16); "I went back to school and my teachers were annoyed with me" (46); and, "After several fights with the school, I finally got all the tutors I needed for my five core classes" (31). One athlete noted difficulty getting tangible support through workplace accommodations, "I have tried to get work to be on board with 
letting me work from home, something almost everyone at my company can do - at least some of the time, which would be a great relief to me — but they won't even entertain the notion" (5).

\section{Receiving Support}

Athletes shared they received the following support types: network support $(\mathrm{n}=18)$; informational $(\mathrm{n}=12)$; tangible $(\mathrm{n}=$ $10)$; emotional $(n=6)$; and esteem $(n=4)$. Table 2 provides a summary of the support receipt themes.

Network support. Athletes conveyed how they received support through their family members providing both companionship and advocacy. Examples here included, "My mom was the biggest help, and still is. She is constantly fighting with the school to get me everything I need to succeed" (31); "I'm very fortunate to have an amazing family and wife who have seen me through and picked me up when I have had a difficult time in doing so" (51); and, "My family supported me throughout all of this even though they didn't quite understand it" (57). Other athletes revealed how their friends had assisted them, "My friends started going to my parents and they were really worried about me" (46); and:

One friend, I hadn't talked to her in forever, and she just called out of the blue and said that she heard that this had happened, and even though she doesn't really know what to do, she'll always be there to support me (57);

and:

These close friends would call often and sit with me for hours, even though I wasn't able to do much. One of my close friends would occasionally sit with me and read me things off of our favorite websites since he knew I couldn't go on the computer (31).

Some athletes relayed how their teammates and coaches had maintained social contact after the concussion, "This team is as supportive and if they think they have a concussion or any injury they come to me" (41); and, "I couldn't have done any of it without the support of my family, athletic trainers, coaches, and doctors" (58).

Table 2.

Support Receipt Themes

\begin{tabular}{|c|l|l|}
\hline SUPPORT TYPE & \multicolumn{1}{|c|}{ DEFINITION } & \multicolumn{1}{c|}{ EXAMPLE } \\
\hline Informational Support & $\begin{array}{l}\text { Providing factual } \\
\text { information or advice } \\
\text { about a problem }\end{array}$ & $\begin{array}{l}\text { "I decided to get a } \\
\text { primary care physician } \\
\text { who specialized in } \\
\text { sports medicine" }\end{array}$ \\
\hline Emotional Support & $\begin{array}{l}\text { Communicating } \\
\text { camaraderie and } \\
\text { allowing others to vent } \\
\text { negative feelings }\end{array}$ & $\begin{array}{l}\text { "He kept reassuring me } \\
\text { and said that all will be } \\
\text { OK and I will heal" }\end{array}$ \\
\hline
\end{tabular}

\begin{tabular}{|l|l|l|}
\hline \multicolumn{1}{|c|}{ SUPPORT TYPE } & \multicolumn{1}{|c|}{ DEFINITION } & \multicolumn{1}{c|}{ EXAMPLE } \\
\hline Esteem Support & $\begin{array}{l}\text { Bolstering a person's } \\
\text { sense of self-worth }\end{array}$ & $\begin{array}{l}\text { "I am thankful for my } \\
\text { parents for believing in } \\
\text { me when I did not" }\end{array}$ \\
\hline Network Support & $\begin{array}{l}\text { Increasing people's } \\
\text { social resources, often } \\
\text { through Interpersonal } \\
\text { interactions }\end{array}$ & $\begin{array}{l}\text { "My family supported } \\
\text { me throughout all of } \\
\text { this even though they } \\
\text { didn't quite understand } \\
\text { it" }\end{array}$ \\
\hline Tangible Support & $\begin{array}{l}\text { Offering aid to } \\
\text { improve a person's life } \\
\text { circumstances }\end{array}$ & $\begin{array}{l}\text { "When the school } \\
\text { supports you and your } \\
\text { situation, it's definitely } \\
\text { less stressful on } \\
\text { everyone" }\end{array}$ \\
\hline
\end{tabular}

Informational support. Athletes discussed informational support was obtained when they perceived they had obtained answers related to their injury. For instance, "But thank goodness for the diligent doctors and my dedicated family, they finally found out what was wrong with me and ever since then my life has not been the same" (22); and, "I decided to get a primary care physician who specialized in sports medicine" (13).

Tangible support. Athletes disclosed tangible support was received primarily when school officials were accommodating and empathetic to their academic restrictions. For example, "Getting back to school wasn't easy. I was out for a while, but I caught up with my work with my homeschool teachers. I was put on a 504 plan by my doctors to help me get through the school day and to help me to handle my work" (16); "Luckily, I had a professor who specialized in biopsychology and he worked with many people with concussions and was able to help me before my GPA suffered" (34); and, "when the school supports you and your situation, it's definitely less stressful on everyone" (57). One athlete shared how her students helped her manage her concussion, "It sounded crazy to ask other people to be my brain, but it was worth a shot. They took notes while I talked, organized things for me, asked questions when I made no sense, and kept my eyes off a screen as long as possible" (35). Another athlete conveyed, "My boyfriend was over any time he had a chance to be and is always the first one to offer if I need help with anything" (31).

Emotional support. Athletes confided that they received emotional support when others comforted them and re-assured them that they would be able to recover. For instance, "I'm lucky that my coaches are understanding and try to keep me involved as much as possible" (27); "he just comforted me and me to just forget the old me and start a new [name]. That actually helped a lot" (57); "He kept reassuring me and said that all will be OK and I will heal" (47); and, "She was there for me for every emotional breakdown and for every tear I shed" (31).

Esteem support. Athletes also disclosed how others provided support by positively impacting their self-esteem. For example, "I also wouldn't be where I am if it wasn't for the concussion 
community supporting me each and every day, making sure my attitude is also positive and making sure I never feel alone" (16); and, "I am thankful for my parents, for believing in me when I did not" (44).

\section{Discussion}

For athletes, concussions can be a life-altering experience. Beyond the physiological, mental, and social isolation effects, being able to talk about their experiences can be complex and challenging, considering that many athletes find it difficult to report concussions (Cranmer \& LaBelle, 2018; Sanderson, et al., 2017; Weinberg, Vernau, \& Horn, 2013). Researchers have noted the importance of narratives in research (Hartill, 2014). Via online forums, athletes' concussion recovery stories can help illuminate their support needs and inform understanding of how supportive communication can be enacted toward them as they manage concussion recovery.

As the data here suggest, emotional support needs are prominent for athletes as they manage concussion recovery. Specifically, athletes shared a need for validation couched in communication that people sincerely believed they were injured, that they were not trying to "get out" of activities, and that even if people could not understand what the athlete was going through, they could nevertheless provide support. These concerns reflected the "hidden" nature of concussions, as its symptoms are not as visible to the public as other injuries that athletes sustain (Covassin et al., 2004). Previous research has observed that coaches are instrumental in creating a culture that values concussion reporting (Baugh et al. 2014). Accordingly, supportive communication toward athletes recovering from concussion injury can help meet their emotional support needs and simultaneously create a supportive culture. That is, if athletes see coaches are supportive of athletes who report and are managing concussion recovery, it may create a team culture that prompts athletes to be more likely to report concussions (Baugh et al., 2014). Such behavior from coaches also helps establish a culture wherein athletes perceive the "norm" is to report rather than conceal a concussion (Kroshus et al., 2015b).

Additionally, coaches who are supportive of athletes reporting concussions also seem to minimize athletes expediting their rehabilitation so they can return to competition before their concussion effects have dissipated (Baugh et al., 2014). Coaches who communicate that rehabilitation is paramount provide crucial support to athletes by validating their experiences and signaling that the coach understands what the athlete is going through. Coaches also can further communicate to athletes that their playing time will not be taken away due to reporting a concussion, which is one reason athletes withhold reporting concussions (Sanderson et al., 2017). Establishing this culture is imperative for coaches, as athletes appear to believe that coaches are initially supportive of reporting concussion but perceive a decrease in support over time (Baugh et al., 2014). Moreover, this behavior and culture translates to network support, as teammates learn that athletes are valued, rather than derided, for reporting a concussion (Baugh et al., 2014).

As teammates see the supportive culture enacted by the coach, it bolsters their own support provision toward teammates recovering from a concussion. Athletes' narratives in the forums indicated how they benefited from network support from teammates, friends, and family members. This is a noteworthy outcome, as network support is essential to the recovery process of concussions (Covassin et al., 2014). Indeed, previous research suggests that family and friend support is crucial in managing concussion effects (Bloom, et al., 2004; Caron et al., 2013). Other research has observed that athletes reported a lack of attention and isolation as stressors they experienced in recovering from injury (Gould, Bridges, Udry, \& Beck, 1997). Thus, the need for supportive communication was captured by one athlete who disclosed:

When going through freak accidents like this, the most important thing is support from friends and family. Without this support, it is absolutely impossible to recover. During this time, you need your friends and family to step up and help you in whatever ways possible (31).

As emotional support was the most frequent support type sought, but one of the least often received by athletes in the data, a potential disconnect may exist here (Cutrona, 1990). Athletes expressed a need for others to understand their concussion experiences, yet perceived that people did not adequately convey this desired empathy. In fact, some athletes shared that not only was there a lack of empathy and support, but that friends distanced themselves, while teachers and peers expressed skepticism about the legitimacy of their injury. These behaviors have been noted in previous research (Covassin et al., 2014), and coupled with the findings here, suggest that athletes seek acceptance and empathy when recovering from a concussion. Researchers also have observed that teammates have a significant impact on injured athletes' emotional states (Udry, Gould, Bridges, \& Tuffey, 1997). Accordingly, teammates should be encouraged to communicate to athletes recovering from concussion injuries about how much the athlete is valued as a member of the team and social group. Support deficits here also could exacerbate risk for athletes, as the lack of understanding and empathy may enhance their social isolation. Consequently, athletes may become unwilling to interact with others, or as one athlete noted, prompt them to aggressively rehabilitate, which could ultimately prolong their recovery.

For athletes in this study, the lack of support appears to be connected to the stigmas associated with concussions. Specifically, perceptions that concussed athletes are exaggerating their symptoms and lack the requisite toughness for athletic 
competition. Such behavior may potentially enflame an athlete's concussion symptoms and signals the need for social support. For instance, Covassin et al. (2014) found that increased social support was associated with decreased anxiety for injured athletes. Thus, when athletes sustain a concussion, it is crucial that relational partners elevate social support to help buffer the physiological, emotional, and mental effects induced by a concussion (Baugh et al., 2014). Certainly, silence or wellmeaning platitudes an athlete perceives as unsupportive may not be intentional communication missteps by relational partners. In fact, these efforts reflect a need for education and programming about athletes' lived experiences with concussion and their social support needs. Indeed, some people may not know how to react to athletes when they are recovering from a concussion, and information about support needs can help ameliorate uncertainty about what kind of support they should provide. For example, athletes expressed a desire for friends and teammates to still associate with them. Meeting this need by educating athletes on how to respond to a peer's concussion may reduce uncertainty about how to interact with teammates managing concussions, provide more effective supportive communication, and build a healthy team culture around concussion management (Baugh et al., 2014). The data also suggest the importance of esteem support with athletes recovering from concussions. Athletes received little esteem support, and as esteem support is centered on validating a person's self-worth, athletes may be at risk to not report concussions in the future, particularly if the response they receive while recovering is one of skepticism and disbelief (Cranmer \& LaBelle, 2018).

\section{Practical Implications}

Athletes' support needs while recovering from a concussion are a crucial area to better understand athletes' lived experiences. Athletes experience a host of mental, emotional, and physiological effects when managing concussion recovery (Baugh et al., 2014). Athletes also can experience social isolation as concussion recovery is often performed outside the confines of team training rooms and other athletic areas common to other injury rehabilitation (Covassin et al., 2014). Additionally, athletes managing concussion recovery appear to be less satisfied with support than athletes rehabilitating from other injuries, due to concussions being less overt to the public and one's social group (Covassin et al., 2014). Consequently, it is important for those who live and work with athletes managing concussion recovery (e.g., coaches, parents, teammates) to enact supportive communication and assess its efficacy. At a minimum, these individuals must ensure they maintain contact with the athlete and do not shut him/her out of social contact.

Networks also are an important consideration for coaches, parents, teammates, friends, family members, and school administrators to understand as they support athletes in their concussion recovery (Bianco, 2001; Johnston \& Carroll, 1998; Udry et al., 1997). Researchers have observed that athletes rely on the support of friends, family members, and teammates as they manage injury (Gould et al., 1997), and it is crucial that these individuals maintain their relationships with athletes during concussion recovery. Indeed, it may be fruitful for these relational partners to increase their communication and contact with athletes recovering from concussions to emphasize that the concussion will not change their relationship. Researchers have observed that teammates play an important role with injured athletes' emotional states (Bloom et al., 2004; Gould et al., 1997). Thus, teammates should be encouraged to reach out to athletes managing concussion recovery and be supportive listeners, given that emotional support includes allowing the person seeking support to vent. For instance, teammates can visit an athlete at his or her home, and to the extent appropriate, invite the athlete to watch the team compete, and perhaps hold social gatherings to which the athlete is invited. These actions can help athletes maintain their sense of camaraderie and team connection as they manage their concussion (Covassin et al., 2014), which may help reduce the stress they experience (Gould et al., 1997). Coaches also can take initiative here to endorse these kinds of activities, which helps reinforce a team culture that supports athletes reporting concussions, as athletes see the injury does not change their value to the group (Baugh et al., 2014).

Tangible support also is an important factor for athletes managing concussion recovery, and in this respect, school administrations play a vital role. Athletes disclosed some of the challenges they encountered obtaining academic accommodations, which exacerbated the symptoms they already were managing. Thus, principals, superintendents, athletic directors, and other school officials should communicate to teachers and other personnel the importance of working with athletes as they work through their concussion injury. Educational programming and training to help teachers enhance their awareness of concussion symptoms is one potential step that can be taken here.

Athletes who experience concussions possess a variety of support needs as they work through this injury. Given the lack of visibility associated with this injury (Covassin et al., 2014), along with uncertainty that may exist with relational partners regarding how they should respond, it is important that support be the primary form of communication to athletes managing concussion recovery. Coaches, parents, teammates, friends, and school administrators collaboratively share responsibility for these efforts. Working together, a supportive culture toward concussions (Baugh et al., 2014) will be cultivated. As this culture is developed through an emphasis on meeting the support needs of athletes managing concussion injuries, a healthier climate toward concussion reporting will be communicated and normalized. Such focus on understanding athletes' lived 
experiences will help shift the culture from marginalizing athletes to supporting them as they report and experience concussion effects.

\section{Limitations and Directions for Future Research}

This research has several limitations, which are now discussed. First, the sample included more female than male athletes. Prior research has examined gender differences in concussion reporting (Sanderson et al., 2017), and additional work could further investigate this gap by exploring gender differences in concussion support. Second, the sample included only those concussion victims who chose to disclose online. While the narratives allowed the researchers to capture the athletes' lived experiences, who utilized the online forums to perhaps escape the stress associated with talking about concussions offline (Yeshua-Katz \& Martin, 2013), broadening participant samples to include both online and offline support may be fruitful. Future research could address this need by utilizing in-person interviews with athletes who have experienced concussions. In-person interviews or focus groups would allow researchers to probe for more detail and perhaps gain more in-depth insights about concussion recovery support needs beyond what athletes choose to reveal in online forums. For example, how much time elapses between the concussion and when they choose to write about it? Lastly, because of the format of these online support groups, the stories these individuals shared were at a single point in time that varied across users - some had just experienced their concussion while others were years removed (however, time passed since concussion did not necessarily mean the victims viewed themselves as "healed"). To add uniformity to the data, it would be helpful for researchers to follow concussion recovery in real time or have fixed points at which all users recount their experiences. Additionally, it also would be beneficial to look at how support varies by sport, age, and socioeconomic status, as these variables could influence the type of support an athlete receives.

\section{References}

Albrecht, T. L., \& Adelman, M. B. (1987). Communicating social support. Newbury Park, CA: Sage.

Anderson, E., \& White, A. (2017). Sport, theory and social problems: A critical introduction ( $2^{\text {nd }}$ ed.). New York, NY: Routledge.

Atwood, M. E., Friedman, A., Meisner, B. A., \& Cassin, S. E. (2018). The exchange of social support on online bariatric surgery discussion forums: A mixed-methods content analysis. Health Communication, 33, 628-635.
Baugh, C. M., \& Shapiro, Z. E. (2015). Concussions and youth football: Using a public health law framework to head off a potential public health crisis. Journal of Law and the Biosciences, 2, 449-458.

Baugh, C. M., Kroshus, E., Daneshvar, D. H., \& Stern, R. A. (2014). Perceived coach support and concussion symptom reporting: Differences between freshmen and non-freshmen college football players. The Journal of Law, Medicine, \& Ethics, 42, 314-322.

Bianco, T. (2001). Social support and recovery from sport injury: Elite skiers share their experiences. Research Quarterly for Exercise and Sport, 72, 376-288.

Blackwell, L. S., Robinson, A. F., Proctor, M. R., \& Taylor, A. M. (2017). Same care, different populations: Returnto-learn practices following concussion in primary and secondary populations. Journal of Child Neurology, 32, 327-333.

Bloom, G. A., Horton, A. S., McCrory, P., \& Johnston, K. M. (2004). Sport psychology and concussion: New impacts to explore. British Journal of Sports Medicine, 38, 519521.

Bolger, N., \& Amarel, D. (2007). Effects of social support visibility on adjustment to stress: Experimental evidence. Journal of Personality and Social Psychology, 92, 458-475.

Caron, J. G., Bloom, G. A., Johnston, K. M., \& Sabiston, C. M. (2013). Effects of multiple concussions on retired National Hockey League players. Journal of Sport \& Exercise Psychology, 35, 168-179.

Cassilo, D., \& Sanderson, J. (2018). From social isolation to becoming an advocate: Exploring athletes' grief discourse about lived concussion experiences in online forums. Communication \& Sport, advance online publication. doi: $10.1177 / 216749518790039$

Charlesworth, H., \& Young, K. (2004). Whey English female university athletes play with pain: Motivations and rationalisations. In K. Young (Ed.), Sporting bodies, damaged selves: Sociological studies of sports-related injuries (pp. 163-180). Bingley, England: Emerald.

Cho, J. Y., \& Lee, E. H. (2014). Reducing confusion about grounded theory and qualitative content analysis: Similarities and differences. The Qualitative Report, 19, 1-20.

Covassin, T., Crutcher, B., Bleecker, A., Heiden, E. O., Dailey, A., \& Yang, J. (2014). Postinjury anxiety and social support among collegiate athletes: a comparison between orthopedic injuries and concussions. Journal of Athletic Training, 49, 462-468 
Crabtree, B., \& Miller W. (1999). Doing qualitative research. Newbury Park, CA: Sage.

Cranmer, G. A., \& LaBelle, S. (2018). Using the disclosure decision-making model to understand high school football players' disclosures of concussion symptoms. International Journal of Sport Communication, 11, 241-260.

Cutrona, C. E. (1990). Stress and social support: In search of optimal matching. Journal of Social \& Clinical Psychology, 9, 3-14.

Cutrona, C. E. (1996). Social support in couples: Marriage as a resource in times of stress. Thousand Oaks, CA: Sage.

Cutrona, C. E., \& Russell, D. W. (1990). Types of social support and specific stress: Toward a theory of optimal matching. In I. G. Sarason, B. R. Sarason, \& G. R. Pierce (Eds.), Social support: An interactional view (pp. 319366). New York, NY: Wiley.

Cutrona, C. E., \& Suhr, J. (1991). Controllability of stressful events and satisfaction with spouse support behaviors. Communication Research, 19, 154-174.

Cutrona, C. E., \& Cole, V. (2000). Optimizing support in the natural network. In L. G. Underwood, S. Cohen, \& B. H. Gottlieb (Eds.), Social support measurement and intervention: A guide for health and social scientists (pp. 278-308). Oxford: Oxford University Press.

Day, K., \& Keys, T. (2008). Starving in cyberspace: A discourse analysis of pro-eating disorder websites. Journal of Gender Studies, 17, 1-15.

DeAndrea, D. C. (2015). Testing the proclaimed affordances of online support groups in a nationally representative sample of adults seeking mental health assistance. Journal of Health Communication, 20, 147-156.

Delenardo, S., \& Terrion, J. L. (2014). Suck it up: Opinions and attitudes about mental illness stigma and help-seeking behaviour of male varsity football players. Canadian Journal of Community Mental Health, 33, 43-56.

Goldsmith, D. (2004). Communicating social support: Advances in personal relationships. New York: Cambridge University Press.

Gough, B. (2015). Men's depression talk online: A qualitative analysis of accountability and authenticity in help-seeking and support formulations. Psychology of Men and Masculinity, 17, 156-164.

Gould, D., Bridges, D., Udry, E., \& Beck, L. (1997). Stress sources encountered when rehabilitating from season-ending ski injuries. The Sport Psychologist, 11, 361-378.
Green-Hamman, S., \& Sherblom, J. C. (2014). The influences of optimal matching and social capital on communicating support. Journal of Health Communication, 19, $1130-1144$.

Green-Hamman, S., Eichhorn, K. C., \& Sherblom, J. C. (2011). An exploration of why people participate in Second Life social support groups. Journal of Computer-Mediated Communication, 16, 465-491.

Hallett, R. E., \& Barber, K. (2014). Ethnographic research in a cyber era. Journal of Contemporary Ethnography, 43, 306-330.

Han, J. Y., Kim, J. H., Yoon, J. H., Shim, M., McTavish, F. M., \& Gustafson, D. H. (2012). Social and psychological determinants of levels of engagement with an online breast cancer support group: Posters, lurkers, and nonusers. Journal of Health Communication, 17, 356-371.

Hanna, E., \& Gough, B. (2016). Emoting infertility online: A qualitative analysis of men's forum posts. Health, 20, 363-382.

Hartill, M. (2014). Exploring narratives of boyhood sexual subjection in male-sport. Sociology of Sport Journal, 31, 23-43.

High, A. C., \& Steuber, K. R. (2014). An examination of support (in)adequacy: Types, sources, and consequences of social support among infertile women. Communication Monographs, 81, 157-178.

Horton, A. S., Bloom, G. A., \& Johnston, K. M. (2002). The impact of support groups on the psychological state of athletes experiencing concussions. Medicine \& Science in Sports \& Exercise, 34, S99.

House, J. (1981). Work stress and social support. Reading, MA: Addison-Wesley.

Johnson, S. A. (2015). "Intimate mothering publics": Comparing face-to-face support groups and Internet use for women seeking information and advice in the transition to first time motherhood. Culture, Health \& Sexuality, 17, 237-251.

Johnston, L., \& Carroll, D. (1998). The provision of social support to injured athletes: A qualitative analysis. Journal of Sport Rehabilitation, 7, 267-284.

Kasamatsu, T. M., Valovich McLeod, T., Register-Mihalik, J. K., \& Welch Bacon, C. E. (2017). Teachers' beliefs and practices regarding academic support following concussion. Teaching and Teacher Education, 68, 181-189. 
Kassing, J. W., \& Sanderson, J. (2009). "You're the kind of guy that we all want for a drinking buddy": Expressions of parasocial interaction on Floydlandis.com. Western Journal of Communication, 73, 182-203.

Kerr, Z. Y., Register-Mihalik, J. K., Kay, M. C., DeFreese, J. D., Marshall, S. W., \& Guskiewicz, K. M. (2018). Concussion nondisclosure during professional career among a cohort of former National Football League. The American Journal of Sports Medicine, 46, 22-29.

Kroshus, E., \& Baugh, C. M. (2015). Concussion education in U.S. collegiate sport. Health Education \& Behavior, 43, 182-190.

Kroshus, E., Kerr, Z. Y., DeFreese, J. D., \& Parsons, J. T. (2017). Concussion knowledge and communication behaviors of collegiate wrestling coaches. Health Communication, 32, 963-969.

Kroshus, E., Kubzansky, L. D., Goldman, R. E., \& Austin, S. B. (2015a). Norms, athletic identity, and concussion symptom under-reporting among male collegiate ice hockey players: A prospective cohort study. Annals of Behavioral Medicine, 49, 95-103.

Kroshus, E., Baugh, C. M., Daneshvar, D. H., Nowinski, C. J., \& Cantu, R. C. (2015b). Concussion reporting intention: A valuable metric for predicting reporting behavior and evaluating concussion education. Clinical Journal of Sport Medicine, 3, 243-247.

Kroshus, E., Garnett, B., Hawrilenko, M., Baugh, C. M., \& Calzo, J. P. (2015c). Concussion under-reporting and pressure from coaches, teammates, fans, and parents. Social Science \& Medicine, 134, 66-75.

Langlois, J. A., Rutland-Brown, W., \& Wald, M. M. (2006). The epidemiology and impact of traumatic brain injury: A brief overview. Journal of Head Trauma Rehabilitation, $21,375-378$.

Liston, K., McDowell, M., Malcolm, D., Scott-Bell, A., \& Waddington, I. (2016). On being 'head strong': The pain zone and concussion in non-elite rugby union. International Review for the Sociology of Sport. Advance online publication. doi: 10.1177/1012690216679966

MacDonald, J., Patel, N., Young, J., \& Stuart, E. (2018). Returning adolescents to driving after sports-related concussions: What influences physician decision-making? The Journal of Pediatrics, 194, 177-181.

McCosker, A. (2018). Engaging mental health online: Insights from beyondblue's forum influencers. New Media \& Society, 20, 4748-4764.
McCrory, P., Meeuwisse, W., Dvorak, J., Aubry, M., Bailes, J., Broglio, S., \& Vos, P. E. (2017). Consensus statement on concussion in sport-The 5th international conference on concussion in sport held in Berlin, October 2016. British Journal of Sports Medicine, 51, 15571558.

Meng, J., Chung, M., \& Cox, J. (2016). Linking network structure to support messages: Effects of brokerage and closure on received social support. Journal of Communication, 66, 982-1006.

Nabi, R. L., Prestin, A., \& So, J. (2013). Facebook friends with (health) benefits? Exploring social network site use and perceptions of social support, stress, and well-being. Cyberpsychology, Behavior, and Social Networking, 16, 721-727.

Price, S. L., Aston, M., Monaghan, J., Sim, M., Murphy, G. T., Etowa, J., Pickles, M., Hunter, A., \& Little, V. (2018). Maternal knowing and social networks: Understanding first-time mothers' search for information and support through online and offline social networks. Qualitative Health Research, 28, 1552-1563.

Priem, J. S., \& Solomon, D. H. (2015). Emotional support and physiological stress recovery: The role of support matching, adequacy, and invisibility. Communication Monographs, 82, 88-112.

Rains, S. A. (2014). The implications of stigma and anonymity for self-disclosure in health blogs. Health Communication, 29, 23-31.

Rohde, J. A., Wang, Y., Cutino, C. M., Dickson, B. K., Bernal, M. C., Bronda, S. \& Farraye, F. A. (2018). Impact of disease disclosure on stigma: An experimental investigation of college students' reactions to inflammatory bowel disease. Journal of Health Communication, 23, 91-97.

Sanderson, J., Weathers, M., Snedaker, K., \& Gramlich, K. (2017). "I was able to do my job on the field and keep playing:" A case study investigating female and male athletes' experiences with (not) reporting concussions. Communication \& Sport, 5, 267-287.

Scambler, G., \& Hopkins, A. (1986). Being epileptic: Coming to terms with stigma. Sociology of Health \& Illness, 8 , 26-43.

Steinfeldt, J. A., Vaughan, E. L., LaFollette, J. R., \& Steinfeldt, M. C. (2012). Bullying among adolescent football players: Role of masculinity and moral atmosphere. Psychology of Men \& Masculinity, 13, 340-353. 
Tanis, M. (2008). Health-related on-line forums: What's the big attraction? Journal of Health Communication, 13, 698714.

Toller, P. (2011). Bereaved parents' experiences of supportive and unsupportive communication. Southern Communication Journal, 76, 17-34.

Trujillo, M. (1991). Hegemonic masculinity on the mound: Media representations of Nolan Ryan and American sports culture. Critical Studies in Mass Communication, 9, 290-308.

Udry, E., Gould, D., Bridges, D., \& Tuffey, S. (1997). People helping people? Examining the social ties of athletes coping with burnout and injury stress. Journal of Sport \& Exercise Psychology, 19, 3368-395.

Varga, M. A., \& Paulus, T. M. (2014). Grieving online: Newcomers' constructions of grief in an online support group. Death Studies, 38, 443-449.

Walther, J. B. (2002). Research ethics in internet-enabled research: Human subjects issues and methodological myopia. Ethics and Information Technology, 4, 205-216.

Weinberg, R., Vernau, D., \& Horn, T. (2013). Playing through pain and injury: Psychological considerations. Journal of Clinical Sport Psychology, 7, 41-59.

Wright, K. B., \& Rains, S. A. (2013). Weak-tie support network preference, health-related stigma, and health outcomes in computer-mediated support groups. Journal of Applied Communication Research, 41, 309-324.

Xu, Y., \& Burleson, B. R. (2001). Effects of sex, culture, and support type on perceptions of spousal social support. An assessment of the "support gap" hypothesis in early marriage. Human Communication Research, 24, 535566.

Yeshua-Katz, D., \& Martins, D. (2013). Communicating stigma: The pro-ana paradox. Health Communication, 28, 499508.

Zhao, X., \& Basnyat, I. (2018). Online social support for "Danqin Mama": A case study of parenting discussion forum for unwed single mothers in China. Computers in Human Behavior, 80, 12-21. 


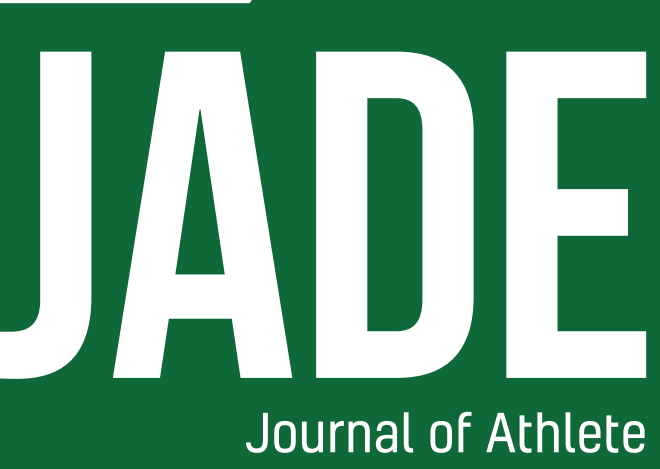

Development and Experience
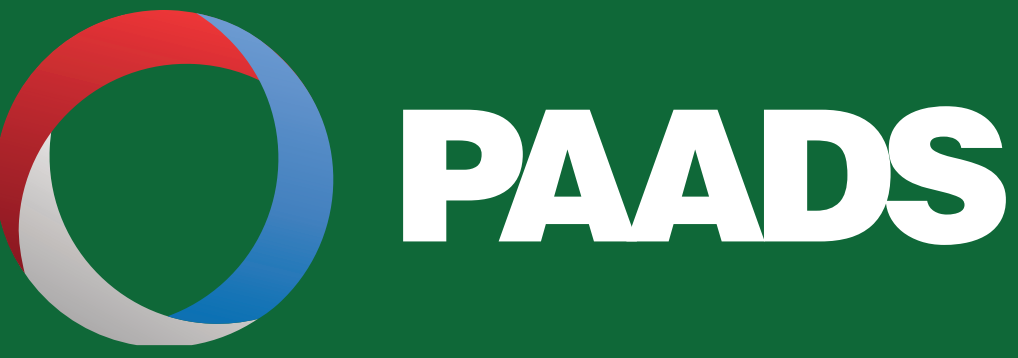

\section{BGSU.}

Bowling Green State University

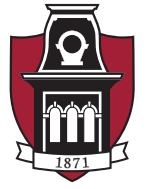

U N I VE R S I TY O F ARKANSAS

College of Education

\& Health Professions

Department of Health,

Human Performance \&

$$
\text { Recreation }
$$

